\title{
Erratum to: Delayed post-operative tension pneumocephalus and pneumorrhachis
}

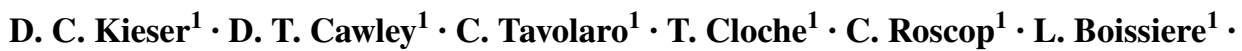
I. Obeid ${ }^{1} \cdot$ V. Pointillart ${ }^{1} \cdot$ J. M. Vital ${ }^{1} \cdot$ O. Gille $^{1}$

Published online: 11 October 2017

(c) Springer-Verlag GmbH Germany 2017

\section{Erratum to: Eur Spine J}

DOI 10.1007/s00586-017-5268-3

Unfortunately, two author names were missed out in author group of the original publication.

The complete author names are given below.

Cecile Roscop

Louis Boissiere

The original article is updated. 